\title{
Change in Chlorophyll Content Over Time Well-differentiated Salt-tolerant, Moderately Salt-tolerant, and Salt- susceptible Cowpea Genotypes
}

\author{
Lingdi Dong ${ }^{1}$ \\ Department of Horticulture, University of Arkansas, Fayetteville, AR 72701; \\ and Institute of Economic Crops, Hebei Academy of Agricultural and \\ Forestry Sciences, Shijiazhuang, 050031, China
}

Waltram Ravelombola ${ }^{\mathbf{1}}$ and Yuejin Weng

Department of Horticulture, University of Arkansas, Fayetteville, AR 72701

Jun Qin

Department of Horticulture, University of Arkansas, Fayetteville, AR 72701; and Institute of Cereal \& Oil Crop, Hebei Academy of Agricultural and Forestry Sciences, Shijiazhuang, Hebei 050031, China

Wei Zhou, Gehendra Bhattarai, Bazgha Zia, and Wei Yang Department of Horticulture, University of Arkansas, Fayetteville, AR 72701

\section{Linqi Shi}

Institute of Economic Crops, Hebei Academy of Agricultural and Forestry Sciences, Shijiazhuang, 050031, China

Beiquan Mou

U.S. Department of Agriculture, Agricultural Research Service, 1636 East Alisal Street, Salinas, CA 93905

\section{Ainong Shi ${ }^{2}$ \\ Department of Horticulture, University of Arkansas, Fayetteville, AR 72701}

Additional index words. Vigna unguiculata, breeding, salinity, tolerance

\begin{abstract}
Previous investigations showed that accumulations of $\mathrm{Na}^{+}$and $\mathrm{Cl}^{-}$in leaves resulted in reductions in chlorophyll content, thereby affecting photosynthesis. Understanding how chlorophyll content evolves over time will help plant breeders to select cowpea genotypes with better tolerance to salinity by allowing them to choose those with more stable chlorophyll content under salt stress. The objective of this study was to assess how the chlorophyll content of cowpea genotypes changed over the course of $24 \mathrm{~d}$ of salt stress at the seedling stage. A total of 24 cowpea genotypes with different salt responses were used in this study. The experiment used a split-plot design with salt treatment as the main plot and cowpea genotypes as the subplot. In the main plot, there were two salt treatments: 0 mm (ionized water) and $200 \mathrm{~mm} \mathrm{NaCl}$. In the subplot, the cowpea genotypes were arranged as a completely randomized design with three replicates per genotype. The results revealed that: a1) the time $\times$ genotype interaction was significant under conditions with and without salt; 2) chlorophyll content slowly decreased in the salt-tolerant genotypes; 3) chlorophyll content slightly increased on day 6 and day 9 of salt stress in both moderate and sensitive genotypes, but it decreased at a faster rate than in the salt-tolerant genotypes; and 4) salt-sensitive genotypes were completely dead on day 24 of salt stress, whereas the salt-tolerant genotypes were able to maintain a significant amount of chlorophyll content. These results can be used to advance breeding programs for salt tolerance in cowpea.
\end{abstract}

Cowpea [Vigna unguiculata (L.) Walp] is one of the most consumed legumes in Africa (Singh et al., 2003). A total of 5.4 million

\footnotetext{
Received for publication 15 Jan. 2019. Accepted for publication 13 Feb. 2019.

${ }^{1}$ These authors contributed equally to this work. ${ }^{2}$ Corresponding authors. E-mail: ashi@uark.edu or Beiquan.Mou@ARS.USDA.GOV.
}

metric tons of cowpea seed is produced globally every year (Olufajo, 2012). Seventy percent of cowpea seed is provided by Africa, and Nigeria is the leading producer (Singh et al., 2003). Even though cowpea cultivation is prevalent in Africa, other regions such as Asia, Oceania, southern Europe, the United States, Central America, and South America are also suitable for cowpea growth (Perrino et al., 1993;
Watt et al., 1985). Cowpea use depends on the region. Fresh pods are most desired in southern Europe (Karapanos et al., 2017), whereas consumption of dried seeds and leaves is common in Africa (Nielsen et al., 1997). In the western part of the United States, there is interest in developing cowpea cultivars as a cover crop (Wilson et al., 2006). Furthermore, previous reports have shown that cowpea is an excellent cover crop (Abdul-Baki et al., 1998; Hutchinson and McGiffen, 2000).

Cowpea is a highly genetically diverse crop consisting of more than 30,000 accessions worldwide (Karapanos et al., 2017), which is critical for establishing a strong breeding program to enhance cowpea variety. Xiong et al. (2016) investigated the population structure existing within a set of 768 cowpea genotypes collected from more than 56 countries. Results showed three distinct subpopulations. These findings will help cowpea breeders select cowpea parents and create further improvements in cowpea cultivars. However, little has been accomplished regarding the study of the responses of cowpea accessions to abiotic stresses such as salt tolerance, which constrains breeders from using the rich genetic resources of cowpea.

Salt stress adversely impacts crop production worldwide by causing physiological abnormalities and reducing growth and yield (Allakhverdiev et al., 2000; Chinnusamy et al., 2005; Flowers, 2004; Osmond et al., 1987). Because cowpea is a drought-tolerant crop, its cultivation is prevalent in the semiarid regions of the sub-Saharan areas in Africa (Karapanos et al., 2017). However, soil salinity is severe in those regions because the low rainfall has resulted in poorly leached salt compounds (Zhang et al., 2012). In the United States, more than 19.6 million hectares of cultivated lands are affected by salinity (Shannon, 1997). Evidence of the growing threat imposed by salinity-related issues for cowpea production has been reported in the Coachella Valley of California (Bower et al., 1969). Wilson et al. (2006) reported that salinity impaired cowpea physiology and growth, thus limiting its use as a potential cover crop. A total of 12 cowpea cultivars in the United States, 'CB5', 'CB27', 'CB46', 'IT89KD-288', 'IT93K-503-1', 'Iron Clay', 'Speckled Purple Hall', 'UCR 134', 'UCR 671', 'UCR 730', '8517', and '7964', were evaluated by Wilson et al. (2006) to determine salt tolerance based on above-ground trait reduction. Significant differences in leaf area, leaf dry weight, stem dry weight, and root dry weight were found among the cowpea cultivars. 'UCR 134' was the most salt-tolerant cultivar, whereas 'UCR 671' was the most salt-sensitive one.

Praxedes et al. (2009) reported that photosynthesis activity was unfavorably affected by salinity in cowpea seedlings, and that cowpea salt-tolerant cultivars had the ability to prevent $\mathrm{Na}^{+}$from being accumulated in leaves. Leaf chlorosis is one of the best 
parameters for evaluating crop tolerance to salinity at the seedling stage (Valencia et al., 2008; Zeng et al., 2017). Measuring the chlorophyll content is one way to determine salt tolerance. However, little has been accomplished regarding the evaluation of chlorophyll content in cowpea, which could be a limitation pertaining to salt tolerance in breeding programs. Less impaired photosynthesis activity under salt stress permits better carbon assimilation in salt-tolerant cowpea cultivars. Because the seedling stage is one of the most sensitive stages of plant growth and development, and because chlorophyll content is highly correlated with salt tolerance for plants treated with salt solution (Valencia et al., 2008), evaluating the chlorophyll content is a significant step toward screening for salt-tolerant cowpea genotypes. Understanding how the chlorophyll content evolves over time in cowpea genotypes with contrasting responses to salt stress could provide key information regarding the genetics of salt tolerance in cowpea, thus substantially advancing cowpea breeding for salt tolerance. Therefore, the objective of this study was to evaluate the chlorophyll content in cowpea seedlings over time.

\section{Materials and Methods}

Plant materials. A total of 24 cowpea genotypes were used for this study. Of these, six were salt-tolerant genotypes, 12 were moderately salt-tolerant, and six were salt-susceptible, as previously reported (Ravelombola et al., 2017) (Supplemental Table 1). The genotypes '09-181', '09529', 'Early Scarlet', and '09-655' were from the University of Arkansas in Fayetteville, whereas the remaining were plant introductions from the U.S. Department of Agriculture (USDA) Germplasm Resources Information Network (GRIN) cowpea germplasm accessions. The USDA Plant Genetic Resources Conservation Unit in Griffin, GA, provided the cowpea seeds, which were increased during the Summers of 2014 and 2015 at the University of Arkansas in Fayetteville, AR.

Growth conditions and salt tolerance phenotyping. Phenotyping of salt tolerance was performed in the Harry R. Rosen Alternative Pest Control greenhouse at the University of Arkansas (Fayetteville, AR). Average day/night temperatures in the greenhouse were $26{ }^{\circ} \mathrm{C} / 21{ }^{\circ} \mathrm{C}$, and daylight length was $14 \mathrm{~h}$. A total of six to eight cowpea seeds were sown in $7-\mathrm{cm}$ plastic square pots containing $85 \mathrm{~g}$ of Sunshine Natural \& Organic (Agawam, MA). The pots containing the cowpea plants were placed in a bigger rectangular plastic tray (Fig. 1). The experiment design was a split-plot with salt treatment as the main plot and cowpea genotypes as the subplot. In the main plot, there were two salt treatments: $0 \mathrm{~mm}$ (ionized water) and $200 \mathrm{~mm}$ $\mathrm{NaCl}$. In the subplot, the cowpea genotypes were arranged as a completely randomized design (CRD) with three replicates per genotype. Upon seedling emergence, plants were thinned to four plants per pot; those with uniform height and exhibiting vigor were kept. Each genotype was irrigated with deionized water or salt-stressed. Salt treatment was performed using a solution of $200 \mathrm{~mm} \mathrm{NaCl}$ (Abeer et al., 2015; Ashebir et al., 2013; Paul et al., 2011), which was obtained by dissolving $11.7 \mathrm{~g}$ of sodium chloride powder (Science Company, Lakewood, CO) in $1 \mathrm{~L}$ of deionized water. Salt stress was first initiated when the first trifoliate leaf started developing (V1 stage) (Fehr et al., 1971). A solution with $100 \mathrm{~mL}$ of 0 or $200 \mathrm{~mm} \mathrm{NaCl}$ was applied to each pot at 2-d intervals over the course of 2 weeks. The experiment with the two treatments was conducted over the course of $24 \mathrm{~d}$.

Measurements. In vivo leaf chlorophyll measurements were performed using a SPAD 02 Plus Chlorophyll Meter (Spectrum Technologies Inc., Plainfield, IL; https:// www.specmeters.com/nutrient-management/ chlorophyll-meters/chlorophyll/spad502p/). Measurements were conducted at 3-d intervals after the first salt treatment was imposed. The last measurement was obtained on day 24 of salt stress, when some plants were completely dead. Chlorophyll measurements were performed three times at different positions on one unifoliate leaf for each plant.

The following parameters were analyzed:

1. Chlorophyll content of genotypes without salt stress over time;

2. Chlorophyll content of genotypes under salt stress over time; and

3. Relative salt tolerance $=$ chlorophyll of salt-stress plants/chlorophyll of nonsalttreated plants.

Data analysis. Data were analyzed using an analysis of variance (ANOVA) with repeated measures as described by Littell et al. (2000). The day of salt stress was used for repeated measures. ANOVA with repeated measures was performed using PROC MIXED in SAS 9.4 (SAS Institute Inc., Cary, NC). Before ANOVA, a covariance structure matrix was determined using SAS 9.4 (SAS Institute Inc.) because the analysis involved repeated measures (Littell et al., 2000). ANOVA was performed using the covariance matrix structure model with the lowest bias-corrected small sample Akaike information criterion (AIC) (Littell et al., 2000).

Covariance matrix structure types were unstructured, independence with equal variance, first-order autoregressive, Toeplitz, Toeplitz with two bands, Toeplitz with three bands, heterogeneous independence, and heterogeneous first autoregressive (Littell et al., 2000). AIC-related values for each covariance matrix structure were computed using the following options in SAS 9.4 (SAS Institute Inc.): type $=$ un, type $=\mathrm{vc}$, type $=\operatorname{ar}(1)$, type $=$ toep, type $=\operatorname{toep}(2)$, type $=\operatorname{toep}(3)$, type $=$ un $(1)$, and type $=\operatorname{arh}(1)$.
The statistical model used the following equation:

$$
\mathrm{Y}_{\mathrm{ijk}}=\mu+\mathrm{Gi}+\eta_{\mathrm{k}(\mathrm{i})}+\mathrm{D}_{\mathrm{j}}+\mathrm{GD}_{\mathrm{ij}}+\varepsilon_{\mathrm{ijk}}
$$

where $Y_{i j k}$ was the value of the parameter from the $\mathrm{k}^{\text {th }}$ replication $(\mathrm{k}=1,2,3)$, $\mathrm{i}^{\text {th }}$ genotype $(i=1,2,3 \ldots \ldots, 30)$, and taken on the $\mathrm{j}^{\text {th }}$ day $(\mathrm{j}=3,6,9,12,15,18,21$, and 24$)$; $\mu$ was the overall mean; $G_{i}$ was the genotype effect (fixed effect); $D_{j}$ was the day effect (fixed effect); $G_{\mathrm{ij}}$ was the genotype $\times$ day effect on the response; $\eta_{k(i)}$ was the independent error term associated with genotypes with $\eta_{\mathrm{k}(\mathrm{i})} \sim \mathrm{N}\left(0, \sigma_{\eta}^{2}\right)$; and $\varepsilon_{\mathrm{ijk}}$ was the error term associated the interaction effect with a variance-covariance structure dependent on the AIC value.

Graphs were drawn using the MASS, ggplot 2, labeling, and gridExtra packages of R 3.1.1 (Pinheiro et al., 2010). Descriptive statistics were calculated using the Tabulate options of JMP Genomics 7 (SAS Institute Inc., Cary, NC).

\section{Results}

Covariance matrix structure identification for ANOVA with repeated measure analysis. The covariance matrix structure model under which ANOVA with repeated measures was performed was identified using SAS 9.4 (SAS Institute Inc.). The AIC values of the chlorophyll content of the salt-stressed were 1846.2, $2272.5,2138.1,2111.0,2172.5,2147.3$, 2100.8 , and 1945.8 for unstructured, independence with equal variance, first-order autoregressive, Toeplitz, Toeplitz with two bands, Toeplitz with three bands, heterogeneous independence, and heterogeneous first autoregressive, respectively (Table 1). Because the lowest AIC values were recorded for the unstructured model, an ANOVA with repeated measures was conducted under an unstructured covariance matrix for the chlorophyll content of plants under salt stress. Similar results were found for the chlorophyll content of plants without salt stress. AIC values were $1695.4,1944.8, \quad 1756.6,1730.2,1801.2$, $1775.8,1915.3$, and 1736.5 for the different covariance matrix types involved in this study (Table 1). Regarding relative salt tolerance, AIC values were $-771.7,-331.1,-434.9$, $-500.1,-409.1,-427.1,-551.1$, and -706.7 for unstructured, independence with equal

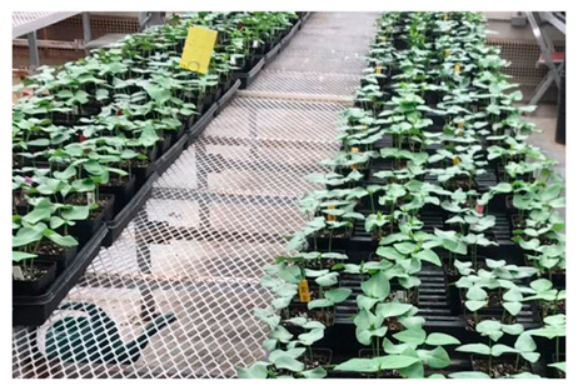

Fig. 1. Overview of greenhouse experiments to evaluate the chlorophyll content over time in cowpea at the seedling stage. 
Table 1. AIC calculations for identifying the best covariance matrix structure.

\begin{tabular}{|c|c|c|c|c|}
\hline Covariance matrix structures & Fits statistics & Chlorophyll, nonstress & Chlorophyll, stress & Relative salt tolerance \\
\hline \multirow[t]{4}{*}{ Unstructured } & -2 Res log likelihood ${ }^{z}$ & 1615.7 & 1769.3 & -851.4 \\
\hline & $\mathrm{AIC}^{\mathrm{y}}$ & 1687.7 & 1841.6 & -779.4 \\
\hline & $\mathrm{AIC}^{\mathrm{x}}$ & 1695.4 & 1846.2 & -771.7 \\
\hline & $\mathrm{BIC}^{\mathrm{w}}$ & 1769.7 & 1923.5 & -697.4 \\
\hline \multirow[t]{4}{*}{ Independence with equal variance } & -2 Res log likelihood & 1942.8 & 2270.5 & -333.1 \\
\hline & $\mathrm{AIC}$ & 1944.8 & 2272.5 & -331.1 \\
\hline & AIC & 1944.8 & 2272.5 & -331.1 \\
\hline & $\mathrm{BIC}$ & 1947 & 2274.7 & -328.8 \\
\hline \multirow[t]{4}{*}{ First order autoregressive } & -2 Res log likelihood & 1752.6 & 2134.1 & -439 \\
\hline & $\mathrm{AIC}$ & 1756.6 & 2138.1 & -435 \\
\hline & AIC & 1756.6 & 2138.1 & -434.9 \\
\hline & $\mathrm{BIC}$ & 1761.2 & 2142.6 & -430.4 \\
\hline \multirow[t]{4}{*}{ Toeplitz } & -2 Res log likelihood & 1713.9 & 2094.6 & -516.5 \\
\hline & $\mathrm{AIC}$ & 1726.9 & 2110.6 & -500.5 \\
\hline & AIC & 1730.2 & 2111 & -500.1 \\
\hline & $\mathrm{BIC}$ & 1748.1 & 2128.8 & -482.2 \\
\hline \multirow[t]{4}{*}{ Toeplitz with 2 bands } & -2 Res log likelihood & 1797.8 & 2168.4 & -413.1 \\
\hline & $\mathrm{AIC}$ & 1801.8 & 2172.4 & -409.1 \\
\hline & AIC & 1801.8 & 2172.5 & -409.1 \\
\hline & $\mathrm{BIC}$ & 1806.4 & 2177 & -404.6 \\
\hline \multirow[t]{4}{*}{ Toelplitz with 3 bands } & -2 Res log likelihood & 1769.7 & 2141.2 & -433.2 \\
\hline & $\mathrm{AIC}$ & 1775.7 & 2174.2 & -427.2 \\
\hline & $\mathrm{AIC}$ & 1775.8 & 2147.3 & -427.1 \\
\hline & $\mathrm{BIC}$ & 1782.6 & 2154 & -420.4 \\
\hline \multirow[t]{4}{*}{ Heteregeneous independence } & -2 Res log likelihood & 1898.9 & 2084.4 & -567.5 \\
\hline & $\mathrm{AIC}$ & 1914.9 & 2100.4 & -551.5 \\
\hline & AIC & 1915.3 & 2100.8 & -551.1 \\
\hline & $\mathrm{BIC}$ & 1933.2 & 2118.6 & -533.3 \\
\hline \multirow[t]{4}{*}{ Heterogeneous first-order autoregressive } & -2 Res log likelihood & 1717.9 & 1927.3 & -725.2 \\
\hline & AIC & 1735.9 & 1945.3 & -707.2 \\
\hline & AIC & 1736.4 & 1945.8 & -706.7 \\
\hline & $\mathrm{BIC}$ & 1756.4 & 1965.8 & -686.7 \\
\hline
\end{tabular}

${ }^{\mathrm{z}}$ Maximization of the likelihood function $\mathrm{L}\left(\Theta \mid \mathrm{y}_{1}, \ldots, \mathrm{y}_{\mathrm{n}}\right)$.

${ }^{y}$ Akaike information criterion.

${ }^{\mathrm{x}}$ Bias-corrected small sample Akaike information criterion.

${ }^{\mathrm{w}}$ Bayesian information criterion.

variance, first-order autoregressive, Toeplitz, Toeplitz with two bands, Toeplitz with three bands, heterogeneous independence, and heterogeneous first autoregressive, respectively (Table 1). Therefore, an ANOVA with repeated measures was conducted using an unstructured covariance matrix type for relative salt tolerance as indicated by the model selection criterion (AIC).

Chlorophyll content of salt-stressed plants over time. Salt stress impaired the chlorophyll content in cowpea plants (Fig. 2). The distribution of the chlorophyll content of salt-stressed plants was approximately normally distributed until day 6 of salt stress (Supplemental Fig. 1). Bimodal distributions were recorded on days 9,12 , and 15 of salt stress (Supplemental Fig. 1). After day 18 of salt stress, the chlorophyll content was skewed to lower the chlorophyll content (Supplemental Fig 1). Overall, the chlorophyll content of salt-stressed plants decreased over time (Supplemental Table 2).

Variations in chlorophyll content over time for salt-tolerant, moderately salt-tolerant, and salt-susceptible genotypes are shown in Fig. 3. Overall, before day 9 of salt stress, there was almost no difference between salt-tolerant, moderately salt-tolerant, and salt-susceptible genotypes based on the chlorophyll content (Fig. 3). After day 12 of salt stress, the chlorophyll content of salt-tolerant, moderately salt-tolerant, and salt-susceptible geno- types differentiated from each other. Such differences were significant after day 18 of salt stress (Fig. 3). The chlorophyll content in both moderately salt-tolerant and saltsusceptible accessions increased on day 9 of salt stress (Fig. 4). After day 9 of salt stress, the chlorophyll content of moderately salttolerant genotypes slowly decreased over time, whereas the susceptible genotypes showed a rapid decrease in chlorophyll content over time (Fig. 4). The chlorophyll content of salt-tolerant genotypes decreased at a slower rate than that of the saltsusceptible and moderately salt-tolerant genotypes (Fig. 4). Violin plots were established to achieve better visualization of the magnitude of chlorophyll content differences between salt-tolerant, moderately salt-tolerant, and salt-susceptible cowpea accessions over time. Violin plots showed a moderate magnitude of the chlorophyll content in the aforementioned groups before day 6 of salt stress; however, that magnitude became significant after that time (Fig. 5). The three groups of genotypes were welldifferentiated after day 12 of salt stress; the tolerant genotypes had the highest chlorophyll content. Moderately tolerant and susceptible genotypes were almost similar at day 3 and day 6 of salt stress (Fig. 5). After day 6 of salt stress, moderately salt-tolerant genotypes significantly differed from the salt-susceptible ones (Fig. 5).

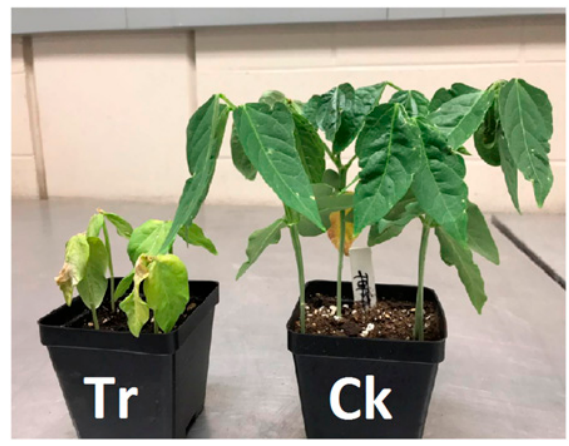

Fig. 2. Significant differences in leaf greenness between salt-treated and nonsalt-stressed plants (Tr: salt-treated plants using $200 \mathrm{~mm} \mathrm{NaCl}$; Ck: plants irrigated with deionized water).

On day 3 of salt stress, the average chlorophyll contents (SPAD values) of salttolerant genotypes ranged from 52.6 (PI $582468)$ to $59.4(09-529)$ and slowly decreased over time. On day 24 of salt stress, SPAD values were 44.2 (PI582468) to 51.2 (PI293545), which were less than the values on day 3 , indicating that the average chlorophyll content decreased under salt stress over time and varied in different accessions (Supplemental Table 1, top section).

For the moderately salt-tolerant genotypes, chlorophyll contents (SPAD values) on day 3 of salt stress ranged from 47.8 


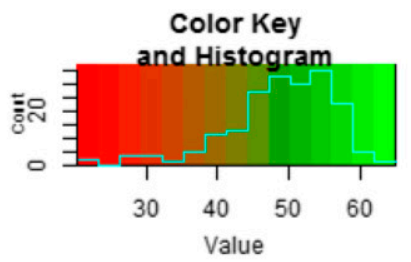

\section{Chlorophyll under salt treatment}
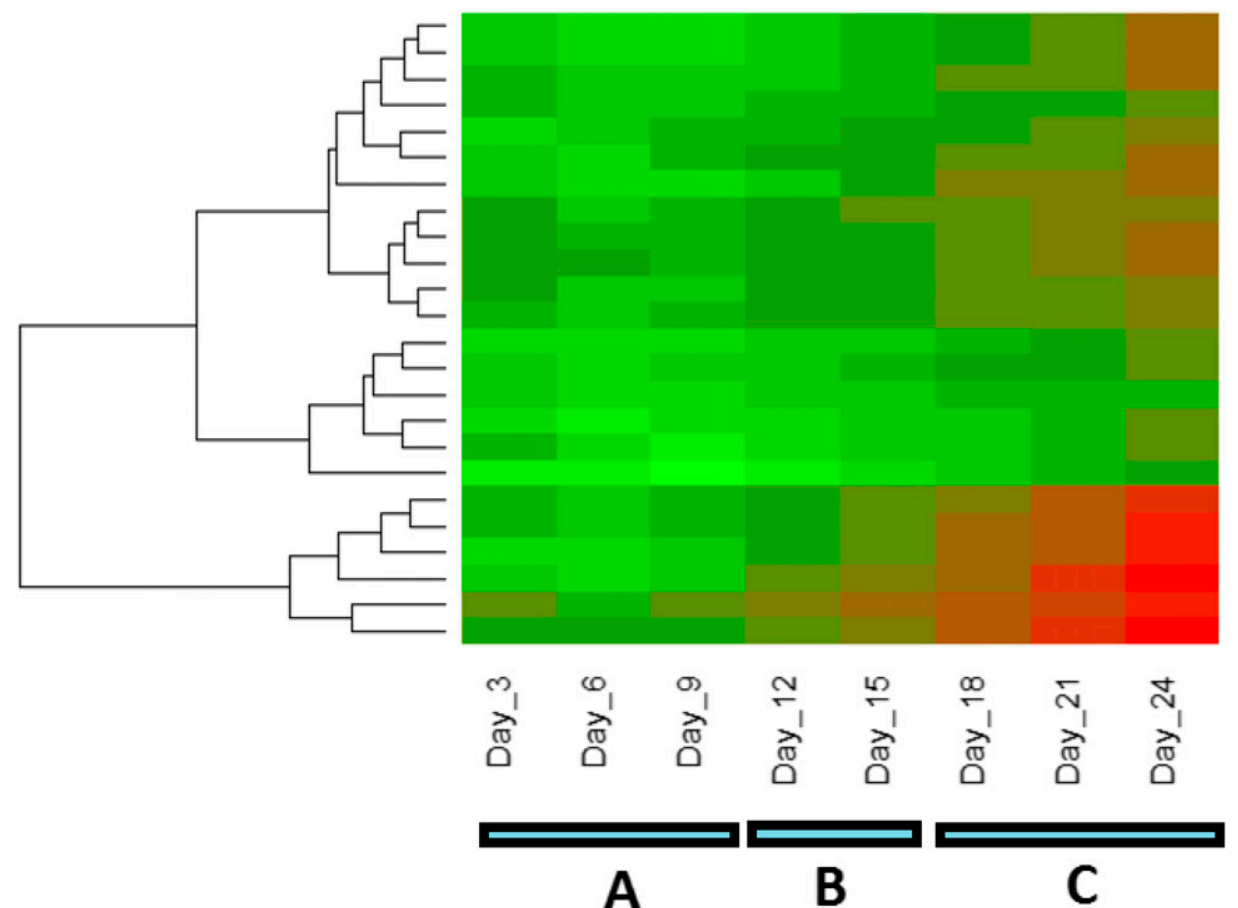

09-655

$\mathrm{PI} 256342$

PI582551

PI582402

PI582575

PI180014

PI582812

PI262179

PI293568

PI583274

PI582340

PI582366

Early_scarlet

09-181

$\mathrm{PI} 293545$

PI666260

PI582468

09-529

PI582852

$\mathrm{PI} 255774$

PI339602

PI430687

PI582573

PI582697

\section{Moderate}

\section{Tolerant}

\section{Susceptible}

Fig. 3. Heatmap showing the change in the chlorophyll content of salt-stressed cowpea genotypes. Accessions were divided into three groups (tolerant, moderate, and susceptible). (A) Almost no differences among the three groups were reported. (B) Cowpea genotypes started differentiating from each other. (C) Clear differences were found between salt-tolerant, moderately salt-tolerant, and salt-susceptible genotypes. On the heatmap, red indicates low chlorophyll content, whereas blue indicates high chlorophyll content.

\section{Chlorophyll under salt stress}

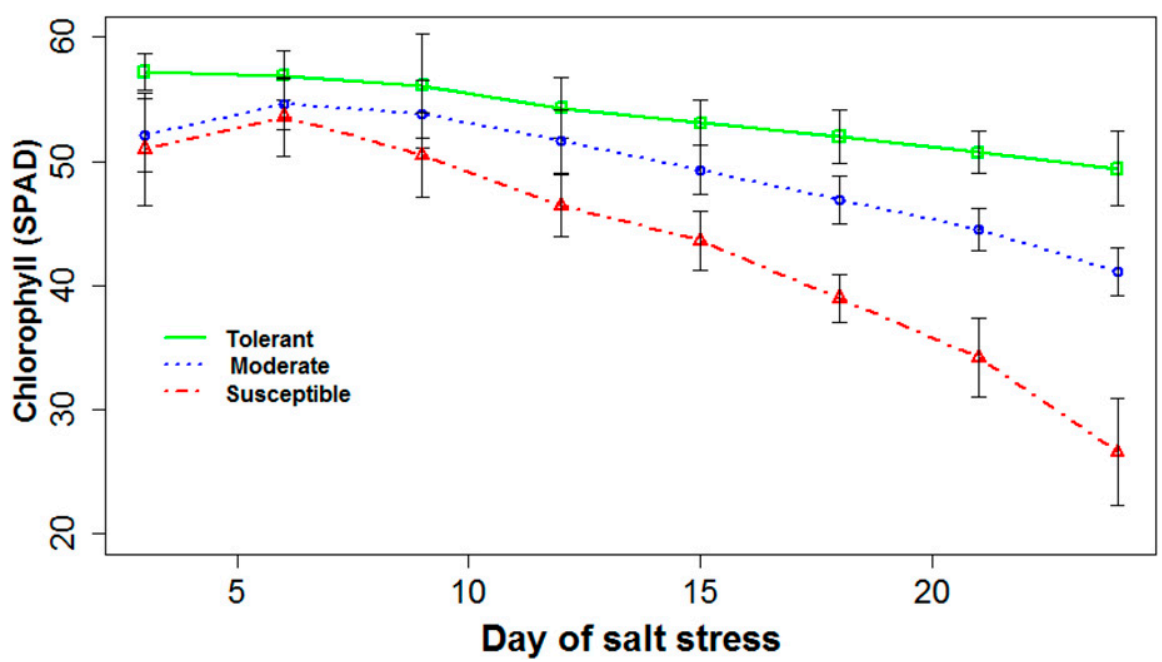

Fig. 4. Curves displaying the pooled chlorophyll contents of plants under salt stress for salt-tolerant, moderately salt-tolerant, and salt-susceptible genotypes.

(PI583274) to 57.2 (PI582575). The results showed an overall increase in the chlorophyll content of the moderately salt-tolerant genotypes on day 6 of salt stress. At that time, those genotypes exhibited the most significant increase in the chlorophyll content among the moderately salt-tolerant genotypes. After day 12 of salt stress, the chloro- phyll content in the moderately salt-tolerant genotypes decreased at a faster rate than that in the salt-tolerant ones (Fig. 4). The chlorophyll contents in the moderately salt-tolerant genotypes on day 24 of salt stress ranged from 39.3 (PI293568) to 42.6 (PI582340) (Supplemental Table 1, top section).

The average chlorophyll contents in the salt-susceptible genotypes on day 3 of salt stress ranged from 44.5 (PI582573) to 57.2 (PI339602) (Supplemental Table 1, top section). A slight increase in the chlorophyll content was recorded for the salt-susceptible genotypes on day 6 of salt stress (Figs. 3 and 4). Of these, genotypes PI255774, PI430687, PI582573, and PI582852 had the most significant increase on day 6 of salt stress (Supplemental Table 1, top section). Among all accessions involved in this study, the chlorophyll content of the salt-susceptible genotypes was most impacted by salt stress on day 24 (Fig. 3). The average chlorophyll contents of salt-susceptible genotypes on day 24 of salt stress ranged from 20.3 (PI582697) to 31.3 (PI582852) (Supplemental Table 1). These results suggested that change in the chlorophyll content over time permitted a clear distinction between salt-tolerant, moderately salt-tolerant, and salt-susceptible genotypes. 
3 days of salt stress

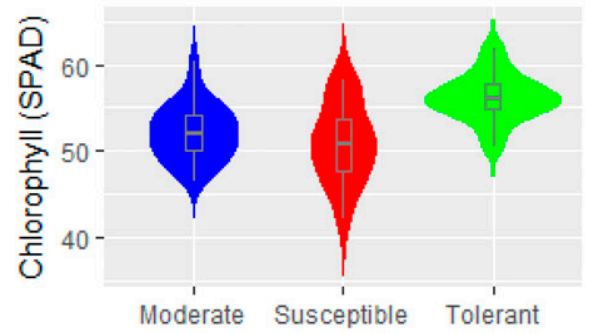

12 days of salt stress

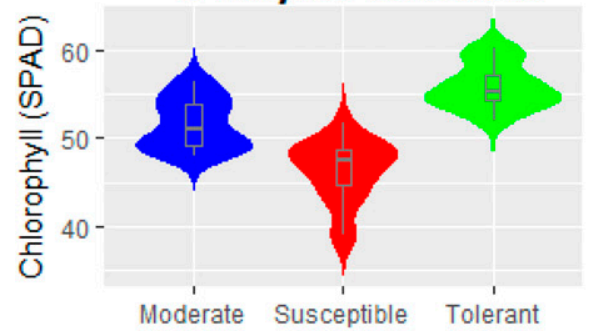

21 days of salt stress

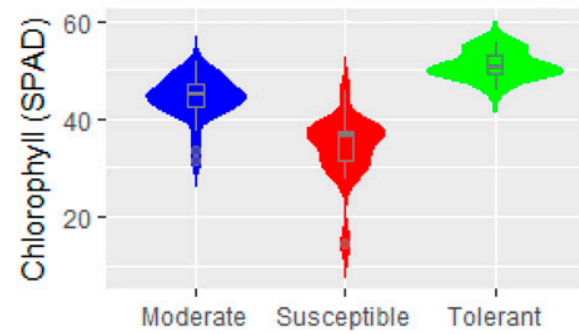

6 days of salt stress

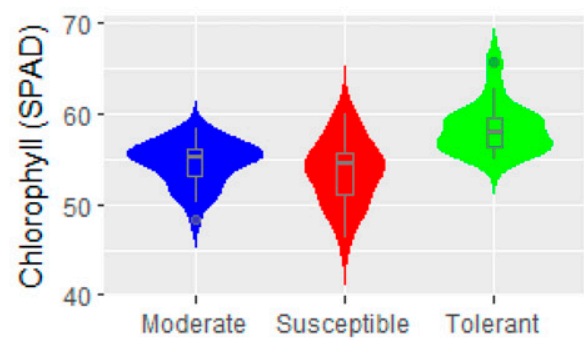

15 days of salt stress

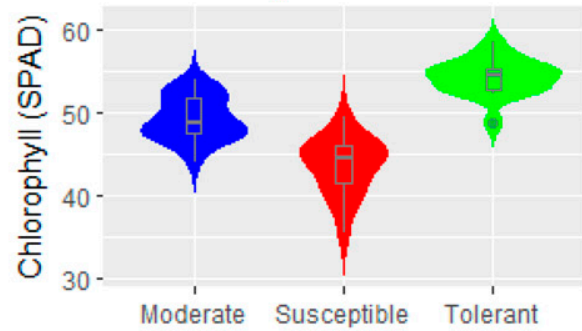

24 days of salt stress

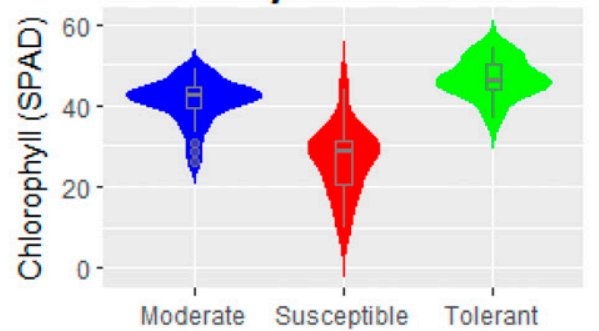

9 days of salt stress

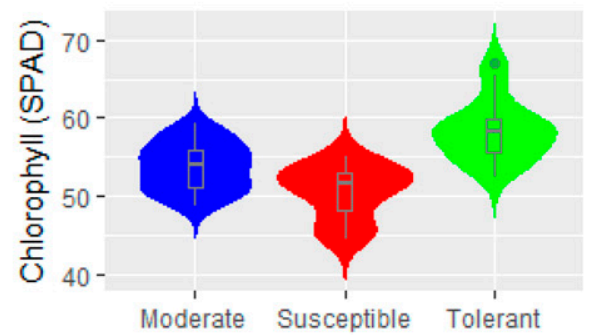

18 days of salt stress

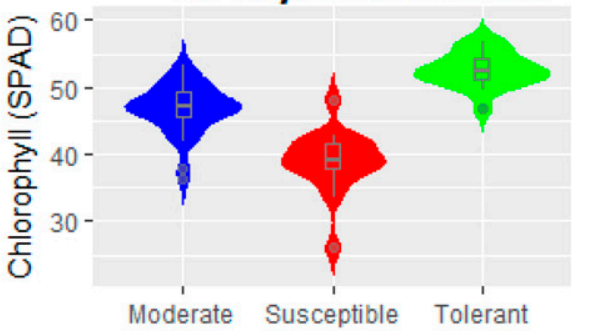

Moderate Susceptible Tolerant

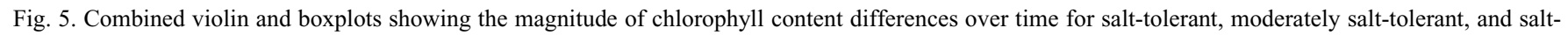
susceptible cowpea genotypes.

The chlorophyll contents were significantly different among the three groups over time under salt stress; the salt-tolerant showed highest level; the moderately salttolerant had the next highest level; and the salt-susceptible had the lowest level (Fig. 4). The salt-susceptible genotypes failed to properly maintain the chlorophyll content within leaves, which led to a rapid decrease in chlorophyll content over time for those genotypes (Fig. 4). In contrast, the salt-tolerant genotypes were capable of maintaining the chlorophyll content within leaves at a level such that survival of those genotypes was possible under prolonged salt stress (Fig. 4).

Chlorophyll content of nonsalt-stressed plants over time. The average chlorophyll content of plants with salt stress was higher than that of plants without salt stress (Supplemental Table 2, Supplemental Fig. 1), indicating that the increase in the chlorophyll content was part of the response of cowpea genotypes to salt stress, which was expected. The average chlorophyll content (SPAD values) with salt stress and that without salt stress had the same trend and similar values. First, there was a slight increase from day 3 to day 6 (highest on day 6). Then, there was a decreased after day 6 . Finally, the smallest value was observed on day 24 (Supplemental Table 2, Supplemental Fig. 1). Furthermore, the large SD resulted in overlaps of the distribution of the chlorophyll values with both treatments (Supplemental Fig. 1), indicating that the chlorophyll content had similar values and the same trend in plants both with and without salt stress.

The ANOVA suggested a significant effect of the genotype $\times$ day interaction on the chlorophyll content of plants with salt stress $(F=2.52 ; P<0.0002)$ and without salt stress $(F=3.22 ; P<0.0001)$ (Table 2$)$. At the end of the experiment, genotypes with the highest chlorophyll content (SPAD values) were PI582366 and 09-529 without salt stress conditions.

Genotypes with the lowest chlorophyll content at the end the experiment were PI582575, PI582573, and PI262179. The chlorophyll content of plants without salt stress was recorded to calculate relative salt tolerance.

Relative salt tolerance for chlorophyll content over time. The relative salt tolerance for the chlorophyll content referred to the ratio between the chlorophyll content of saltstressed plants and those grown without salt stress conditions. The distributions of the relative salt tolerance content over time were approximately normally distributed (Supplemental Table 4, Supplemental Fig. 2). Average values of relative salt tolerance for the chlorophyll content were $1.09,1.09,1.09$, $1.10,1.12,1.15,1.17$, and 1.20 on days 3,6 ,
$9,12,15,18,21$, and 24 of salt stress, respectively (Supplemental Table 2).

Results indicated a significant genotype $\times$ day interaction effect on chlorophyll contents among the cowpea genotypes $(F=2.34 ; P<$ 0.0001 ) (Table 2). Violin plots showed that there was almost no difference between salttolerant, moderately salt-tolerant, and saltsusceptible genotypes before day 9 of salt stress (Fig. 6). After day 15 of salt stress, violin plots corresponding to each group started differentiating from each other; the violin plot of the salt-tolerant genotypes had the highest value (Supplemental Table 1, Fig. 6).

Correlation between chlorophyll contents for plants without salt stress, with salt stress, and relative salt tolerance. Pearson correlation coefficients of the chlorophyll content of salt-stressed plants and the chlorophyll content of nonsalt-treated plants, the chlorophyll content of plants with salt stress with relative salt tolerance, and the chlorophyll content of plants without salt stress with relative salt tolerance over time were calculated. Results showed that correlation coefficients varied over time (Supplemental Table 2); this was consistent with the significant genotype $\times$ day interaction effect that was previously reported.

The correlation between the chlorophyll content of plants with salt stress and without 
Table 2. Analysis of variance (type 3 tests of fixed effects) using an unstructured covariance matrix model for chlorophyll (SPAD) contents of nonsalt-treated plants and salt-stressed plants and relative salt tolerance for chlorophyll content.

\begin{tabular}{|c|c|c|c|c|c|}
\hline$\overline{\text { Parameters }}$ & Effect & Num DF & Den DF & $F$ value & $\operatorname{Pr}>F$ \\
\hline \multirow[t]{2}{*}{ Chlorophyll content without salt stress } & Genotype & 23 & 48 & 14.68 & $<0.0001$ \\
\hline & Genotype $\times$ day & 161 & 48 & 3.22 & $<0.0001$ \\
\hline \multirow[t]{2}{*}{ Chlorophyll content under salt stress } & Genotype & 23 & 48 & 10.81 & $<0.0001$ \\
\hline & Genotype $\times$ day & 161 & 48 & 2.52 & 0.0002 \\
\hline \multirow[t]{2}{*}{ Relative salt tolerance $^{\mathrm{z}}$} & Genotype & 23 & 48 & 14.32 & $<0.0001$ \\
\hline & Day & 7 & 48 & 8.83 & $<0.0001$ \\
\hline
\end{tabular}

${ }^{\mathrm{z}}$ Relative salt tolerance was the ratio between the chlorophyll content of plants under salt stress conditions and those without salt stress.

3 days of salt stress

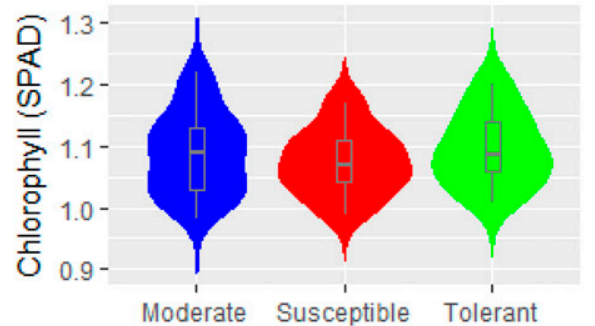

12 days of salt stress

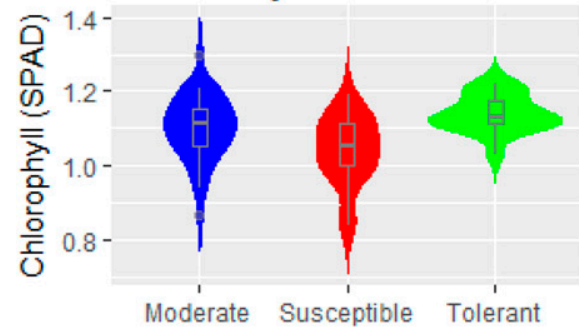

21 days of salt stress

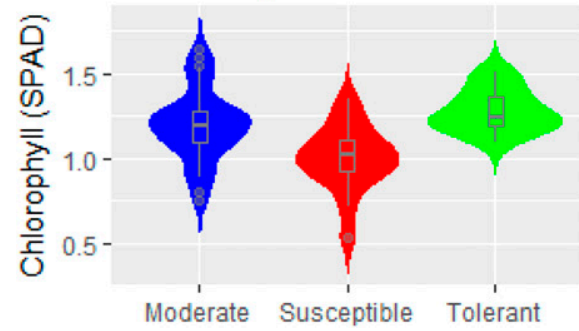

6 days of salt stress

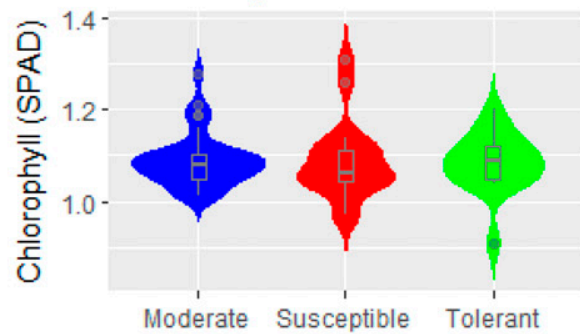

15 days of salt stress

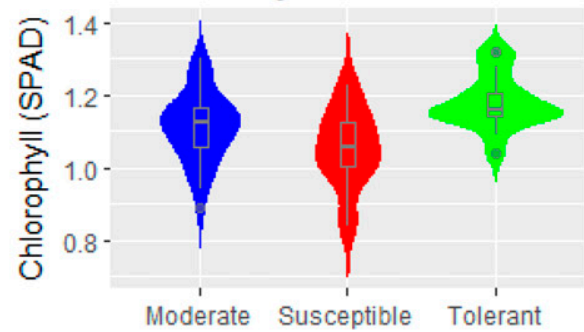

24 days of salt stress

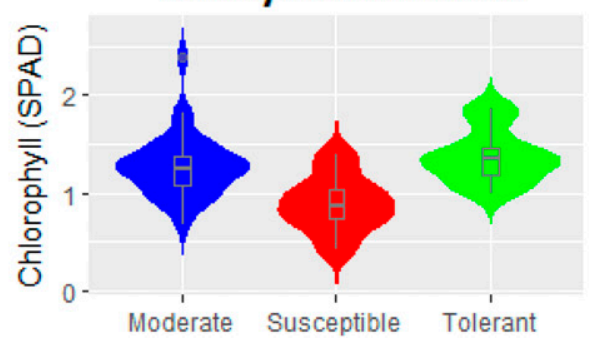

Fig. 6. Combined violin and boxplots showing the magnitude of relative salt tolerance differences over time for salt-tolerant, moderately salt-tolerant, and saltsusceptible cowpea genotypes.

salt stress was high on day 3 of salt stress $(r=$ $0.75)$, indicating that the salt-treated plants were less affected by salt treatment at that time. The correlation coefficient between the chlorophyll content of plants with salt stress and without salt stress was low on day 24 of salt stress $(r=0.28)$, suggesting that cowpea genotypes responded differently to salt stress over time.

Correlation coefficients between the chlorophyll content of salt-treated plants and relative salt tolerance were $0.26,0.22,0.41$, $0.46,0.48,0.50,0.67$, and 0.76 on days 3,6 , $9,12,15,18,21$, and 24 of salt stress, respectively (Supplemental Table 3), which suggested that the chlorophyll content of plants with salt stress was highly correlated with relative salt tolerance on day 24 of salt stress. Therefore, both chlorophyll content with salt stress and relative salt tolerance for chlorophyll content could be used as good phenotypes for screening salt tolerance in cowpea seedlings.

Overall, correlations between the chlorophyll content of plants without salt stress and relative salt tolerance were moderated over time. Such results suggested that the chlorophyll content of plants without salt stress could not predict the tolerance of cowpea genotypes at the seedling stage.

\section{Discussion}

Soil salinity is a growing concern that affects the crop production worldwide (Ghassemi et al., 1995; Reddy et al., 2017).
A scarcity of studies investigating the salt tolerance of cowpea has impaired the development of salt-tolerant cultivars. In this study, we increased the knowledge of the salt tolerance of cowpea by providing responses of a diverse set of cowpea genotypes to salt stress.

The seedling stage is one of the most vulnerable stages during plant growth and development. During this investigation, we assessed the salt tolerance of cowpea at the seedling stage. A large number of studies have accurately evaluated the salt tolerance of plant seedlings. Li et al. (2011) investigated the salt tolerance of tomato (Solanum lycopersicum L.) at the seedling stage. For rice (Oryza sativa L.), phenotyping of salt tolerance at the seedling stage led to the 
discovery of a candidate gene, SST, for salt tolerance (Lan et al., 2015). In addition, salt tolerance phenotyping at the seedling stage was used to find salt-tolerant quantitative trait loci (QTL) in a cotton population derived from a cross between Gossypium tomentosum Nutt. ex Seem. and Gossypium hirsutum L. (Oluoch et al., 2016). Salt tolerance phenotyping at the seedling stage has been extensively conducted in soybean [Glycine max (L.) Merr.] (Ledesma et al., 2016; Zhang et al., 2011).

Praxedes et al. (2009) showed that salt tolerance of cowpea was correlated with the responses to ion accumulation and the regulation of photosynthesis. The differences in chlorophyll content among the genotypes could be explained by the fact that some genotypes might have the ability to limit salt ions from entering the plant system, whereas those with a low chlorophyll content could fail to do so. Zeng et al. (2017) found that soybean genotypes that were able to exclude $\mathrm{Cl}^{-}$were likely to be salt-tolerant, whereas those with a high $\mathrm{Cl}^{-}$leaf concentration were susceptible to salt stress. Valencia et al. (2008) demonstrated that the chlorophyll content was highly correlated with salt ion concentrations within soybean leaves. After $24 \mathrm{~d}$ of salt stress, differences in the chlorophyll content were highly significant among the genotypes, indicating that important salt ions were accumulated within leaves of the susceptible genotypes. Such findings were also consistent with the fact that Person's correlation coefficients for the different traits involved in this analysis varied over time, and a relatively high correlation coefficient was identified between chlorophyll for salttreated plants and relative salt tolerance on day 24 of salt stress.

The results of this investigation will have practical applications because changes in the chlorophyll content over time were shown to help significantly differentiate salt-tolerant, moderately salt-tolerant, and salt-susceptible cowpea genotypes; therefore, these results could be used to improve cowpea breeding programs related to salt tolerance. More importantly, these results provided robust foundations that can assist cowpea geneticists with dissecting the mechanisms of salt tolerance of cowpea. The bulk RNA-seq analysis has become a popular and efficient

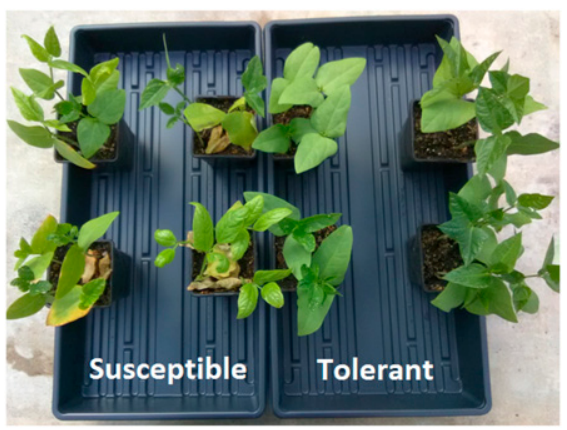

Fig. 7. Cowpea salt-tolerant and salt-susceptible genotypes on day 18 of salt stress. way of identifying plant genes that are expressed under stresses such as salt conditions. However, information regarding the specific timing when phenotypic differences were highest between phenotypically contrasting genotypes has been critical to the successful performance of RNA-seq-related studies. In this report, we have shown that salt-tolerant cowpea genotypes had higher chlorophyll contents even at day 3 of salt stress when compared with both moderately salt-tolerant and salt-susceptible genotypes. The chlorophyll content of both moderately salt-tolerant and salt-susceptible genotypes slightly increased on day 9 of salt stress, as indicated by the violin plots. Therefore, we consider an immediate response of these genotypes initially occurs to cope with salt stress; however, the increase in the chlorophyll content failed to be sustained in these genotypes over time. Interestingly, salt-tolerant cowpea genotypes did not exhibit increased chlorophyll contents on day 9 of salt stress. This discrepancy in the dynamics of the magnitude of the chlorophyll content identified between salt-tolerant, moderately salt-tolerant, and salt-susceptible genotypes on day 9 could provide key information to identify which transcripts are highly expressed at that time, which could lead to either tolerance or susceptibility to salt stress in cowpea. Therefore, this investigation could have a significant impact on attempts to provide insight regarding the genetics of salt tolerance of cowpea, which remain limited. We repeated the experiments for two of the most salt-tolerant (PI582468 and 09-529) and two of the most salt-susceptible genotypes (PI255774 and PI582573) because extreme genotypes were more relevant to further unraveling the mechanisms related to potential major gene effects. Clear differences have been found between these aforementioned genotypes on day 18 of salt stress (Fig. 7), and these were in agreement with our previous results.

\section{Conclusions}

In this study, we investigated variations of the chlorophyll content of 24 genotypes previously reported to have contrasting responses under salt stress. The results indicated a significant genotype $\times$ day interaction effect on the chlorophyll content, indicating that the differences in chlorophyll content under salt conditions could be attributable to the accumulation of salt ions over time. Salt stress significantly decreased the chlorophyll content in cowpea plants. The degree of the decrease in the chlorophyll content varied between salt-tolerant, moderately salt-tolerant, and salt-susceptible genotypes. Interestingly, the chlorophyll contents in moderately salttolerant and salt-susceptible genotypes slight increased after day 6 of salt stress and decreased at a faster rate after that time when compared with salt-tolerant ones. This pattern can assist cowpea breeders when selecting genotypes for better salt tolerance. To the best of our knowledge, no reports have pro- vided information regarding how chlorophyll (SPAD) changes over time could help differentiate salt-tolerant, moderately salt-tolerant, and salt-susceptible genotypes, which is essential in providing good phenotyping strategies for salt tolerance in cowpea.

\section{Literature Cited}

Abdul-Baki, A., S. Aslan, E.H. Beardsley, S. Cobb, and M. Shannon. 1998. Soil, water, and nutritional management of Date Orchards in the Coachella Valley and Bard. Coachella Valley Resour. Conserv. Dist., Indio, CA.

Abeer, H., E.F. Abd-Allah, A.A. Alqarawi, and D. Egamberdieva. 2015. Induction of salt stress tolerance in cowpea [Vigna Unguiculata (L.) Walp.] by arbuscular mycorrhizal fungi. Legume Res. 38(5):579-588.

Allakhverdiev, S.I., A. Sakamoto, Y. Nishiyama, M. Inaba, and N. Murata. 2000. Ionic and osmotic effects of $\mathrm{NaCl}$-induced inactivation of photosystems I and II in Synechococcus sp. Plant Physiol. 123(3): 1047-1056.

Ashebir, G., A. Mebeasilassie, and M. Manikanidan. 2013. The response of some cowpea (Vigna Unguiculata (L.) Walp.) genotypes for salt stress during germination and seedling stage. J. Stress Physiol. Biochem. 9(4):57.

Bower, C.A., J.R. Spencer, and L.O. Weeks. 1969 Salt and water balance. J. Irrig. Drain. Div. ASCE Proc. Paper 6437:55-64.

Chinnusamy, V., A. Jagendorf, and J.K. Zhu. 2005. Understanding and improving salt tolerance in plants. Crop Sci. 45(2):437-448.

Fehr, W.R., C.E. Caviness, D.T. Burmood, and J.S. Pennington. 1971. Stage of development descriptions for soybeans, Glycine Max (L.) Merrill. Crop Sci. 11(6):929-931.

Flowers, T.J. 2004. Improving crop salt tolerance. J. Expt. Bot. 55(396):307-319.

Ghassemi, F., A.J. Jakeman, and H.A. Nix. 1995. Salinisation of land and water resources: $\mathrm{Hu}-$ man causes, extent, management and case studies. CAB Int., Wallingford, Oxon.

González, L.M. 1996. Use of radioinduction of mutations in obtaining salinity-tolerant rice genotypes. PhD Diss (in Spanish). Granma, Cuba.

Hutchinson, C.M. and M.E. McGiffen, Jr. 2000 Cowpea cover crop mulch for weed control in desert pepper production. HortScience 35:196198.

Karapanos, I., A. Papandreou, M. Skouloudi, D. Makrogianni, J.A. Fernández, E. Rosa, G. Ntatsi, P.J. Bebeli, and D. Savvas. 2017. Cowpea fresh pods - a new legume for the market: Assessment of their quality and dietary characteristics of 37 cowpea accessions grown in southern Europe. J. Sci. Food Agr. 97(13):4343-4352.

Lan, T., S. Zhang, T. Liu, B. Wang, H. Guan, Y. Zhou, Y. Duan, and W. Wu. 2015. Fine mapping and candidate identification of SST, a gene controlling seedling salt tolerance in rice (Oryza Sativa L.). Euphytica 205(1):269-274.

Ledesma, F., C. Lopez, D. Ortiz, P. Chen, K.L. Korth, T. Ishibashi, A. Zeng, M. Orazaly, and L.F. Palacios. 2016. A simple greenhouse method for screening salt tolerance in soybean. Crop Sci. 56(2):585-594.

Li, J., L. Liu, Y. Bai, P. Zhang, R. Finkers, Y. Du, R.G.F. Visser, and A.W. van Heusden. 2011. Seedling salt tolerance in tomato. Euphytica 178(3):403-414.

Littell, R.C., J. Pendergast, and R. Natarajan. 2000. Tutorial in biostatistics: Modelling covariance structure in the analysis of repeated measures data. Stat. Med. 19(13):1793-1819. 
Nielsen, S.S., T.A. Ohler, and C.A. Mitchell. 1997. Cowpea leaves for human consumption: Production, utilization, and nutrient composition, p. 326-332. In: B.B. Singh, D.R.M. Raj, K.E. Dashiell, and L.E.N. Jackai (eds.). Advances in Cowpea Research. Ibadan, Nigeria.

Olufajo, O.O. 2012. Agronomic performance of improved cowpea varieties under natural infestation with Alectra Vogelii (Benth.) in the Northern Guinea savannah of Nigeria. Agr. Trop. Subtrop. 45(2):66-71.

Oluoch, G., J. Zheng, X. Wang, M.K.R. Khan, Z. Zhou, X. Cai, C. Wang, Y. Wang, X. Li, H. Wang, and F. Liu. 2016. QTL mapping for salt tolerance at seedling stage in the interspecific cross of Gossypium Tomentosum with Gossypium Hirsutum. Euphytica 209(1):223-235.

Osmond, C.B., M.P. Austin, and J.A. Berry. 1987. Stress physiology and the distribution of plants. Bioscience 37(1):38-48.

Paul, S., A. Kundu, and A. Pal. 2011. Identification and validation of conserved microRNAs along with their differential expression in roots of Vigna Unguiculata grown under salt stress. Plant Cell Tissue Organ Cult. 105(2):233-242.

Perrino, P., G. Laghetti, P.L.S. Zeuli, and L.M. Monti. 1993. Diversification of cowpea in the Mediterranean and other centres of cultivation. Genet. Resources Crop Evol. 40(3):121-132.
Pinheiro, J., D. Bates, S. DebRoy, and D. Sarkar. R Development Core Team. 2010. nlme: Linear and nonlinear mixed effects models. R package version 3.1-97. $\mathrm{R}$ Foundation for Statistical Computing, Vienna.

Praxedes, S.C., C.F.D. Lacerda, F.M. DaMatta, J.T. Prisco, and E.G. Filho. 2009. Salt tolerance is associated with differences in ion accumulation, biomass allocation and photosynthesis in cowpea cultivars. J. Agron. Crop Sci. 196(3):193204.

Ravelombola, W., A. Shi, Y. Weng, B. Mou, D. Motes, J. Clark, P. Chen, V. Srivastava, J. Qin, L. Dong, and W. Yang. 2017. Association Analysis of salt tolerance in cowpea (Vigna unguiculata (L.) walp) at germination and seedling stages. Theor. Appl. Genet. 131(1):79-91.

Reddy, I.N.B.L., B. Kim, I.S. Yoon, K.H. Kim, and T.R. Kwon. 2017. Salt tolerance in rice: Focus on mechanisms and approaches. Rice Sci. 24(3):123-144.

Shannon, M.C. 1997. Adaptation of plants to salinity. Adv. Agron. 60:75-120.

Singh, B.B., H.A. Ajeigbe, S.A. Tarawali, S.F. Rivera, and M. Abubakar. 2003. Improving the production and utilization of cowpea as food and fodder. Field Crops Res. 84(1):169-177.

Valencia, R., P. Chen, T. Ishibashi, and M. Conatser. 2008. A rapid and effective method for screening salt tolerance in soybean. Crop Sci. 48(5): 1773-1779.

Watt, E.E., E.A. Kueneman, and J.P.P.D. Araujo 1985. Achievements in breeding cowpeas in Latin America, p. 125-135. In: S.R. Singh and K.O. Rachie (eds.). Cowpea: Research, production and utilization. John Wiley and Sons, NY.

Wilson, C., X. Liu, S.M. Lesch, and D.L. Suarez. 2006. Growth response of major US cowpea cultivars. I. Biomass accumulation and salt tolerance. HortScience 41:225-230.

Xiong, H., A. Shi, B. Mou, J. Qin, D. Motes, W. Lu, J. Ma, Y. Weng, W. Yang, and D. Wu. 2016. Genetic diversity and population structure of cowpea (Vigna Unguiculata L. Walp). PLoS One 11(8):e0160941.

Zeng, A., L. Lara, P. Chen, X. Luan, F. Hancock, K. Korth, K. Brye, A. Pereira, and C. Wu. 2017. Quantitative trait loci for chloride tolerance in 'Osage' soybean. Crop Sci. 57(5):2345-2353.

Zhang, H.J., H.Z. Dong, W.J. Li, and D.M. Zhang. 2012. Effects of soil salinity and plant density on yield and leaf senescence of field-grown cotton. J. Agron. Crop Sci. 198(1):27-37.

Zhang, X.K., Q.H. Zhou, J.H. Cao, and B.J. Yu. 2011 Differential $\mathrm{Cl}^{-}$salt tolerance and $\mathrm{NaCl}$-induced alternations of tissue and cellular ion fluxes in Glycine max, Glycine soja and their hybrid seedlings. J. Agron. Crop Sci. 197(5):329-339. 

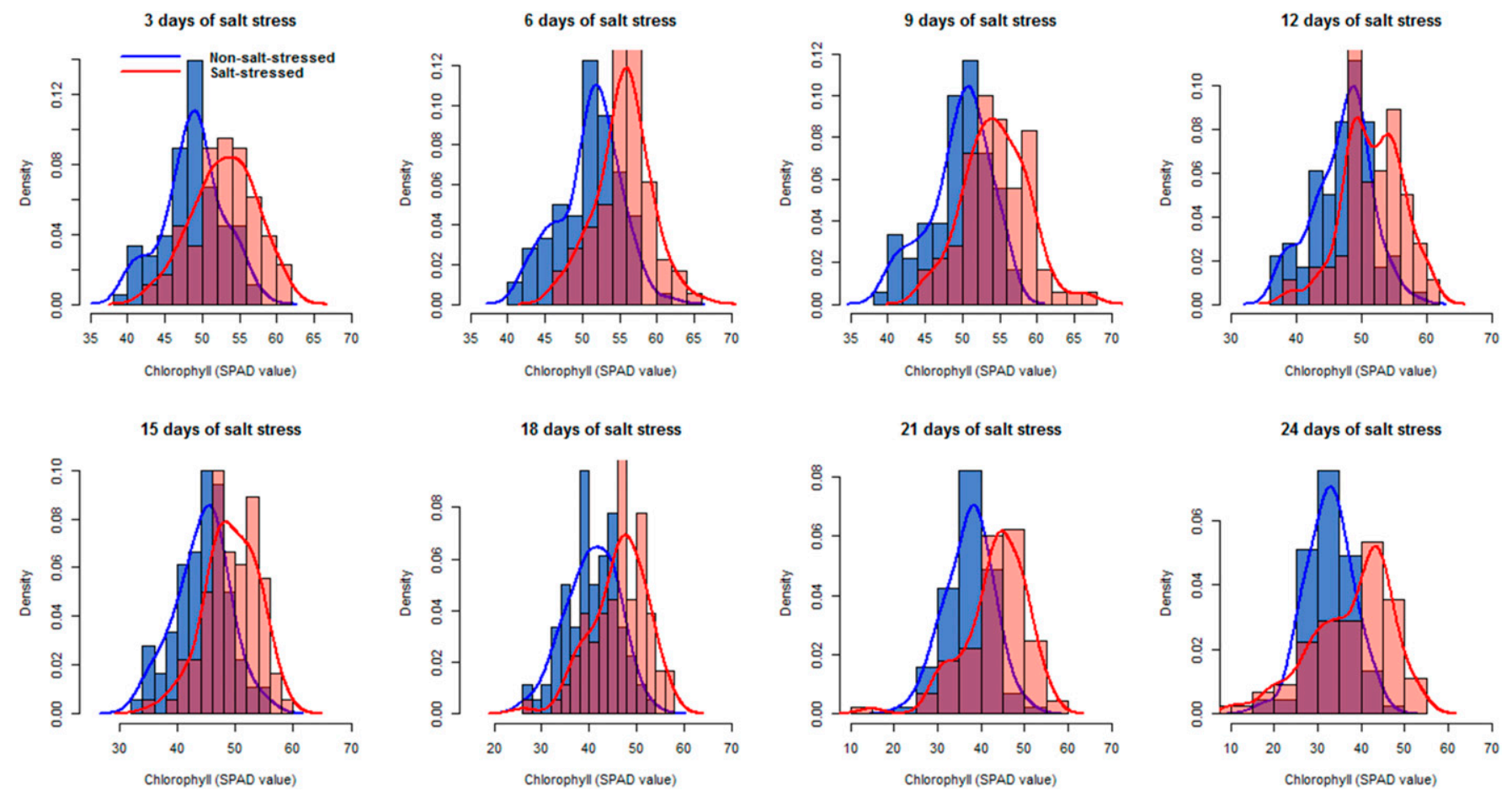

Supplemental Fig. 1. Distributions of the leaf chlorophyll content over time. Blue represents the observations of the nonsalt-treated plants, whereas red indicates those of salt-stressed plants $(200 \mathrm{~mm} \mathrm{NaCl})$.
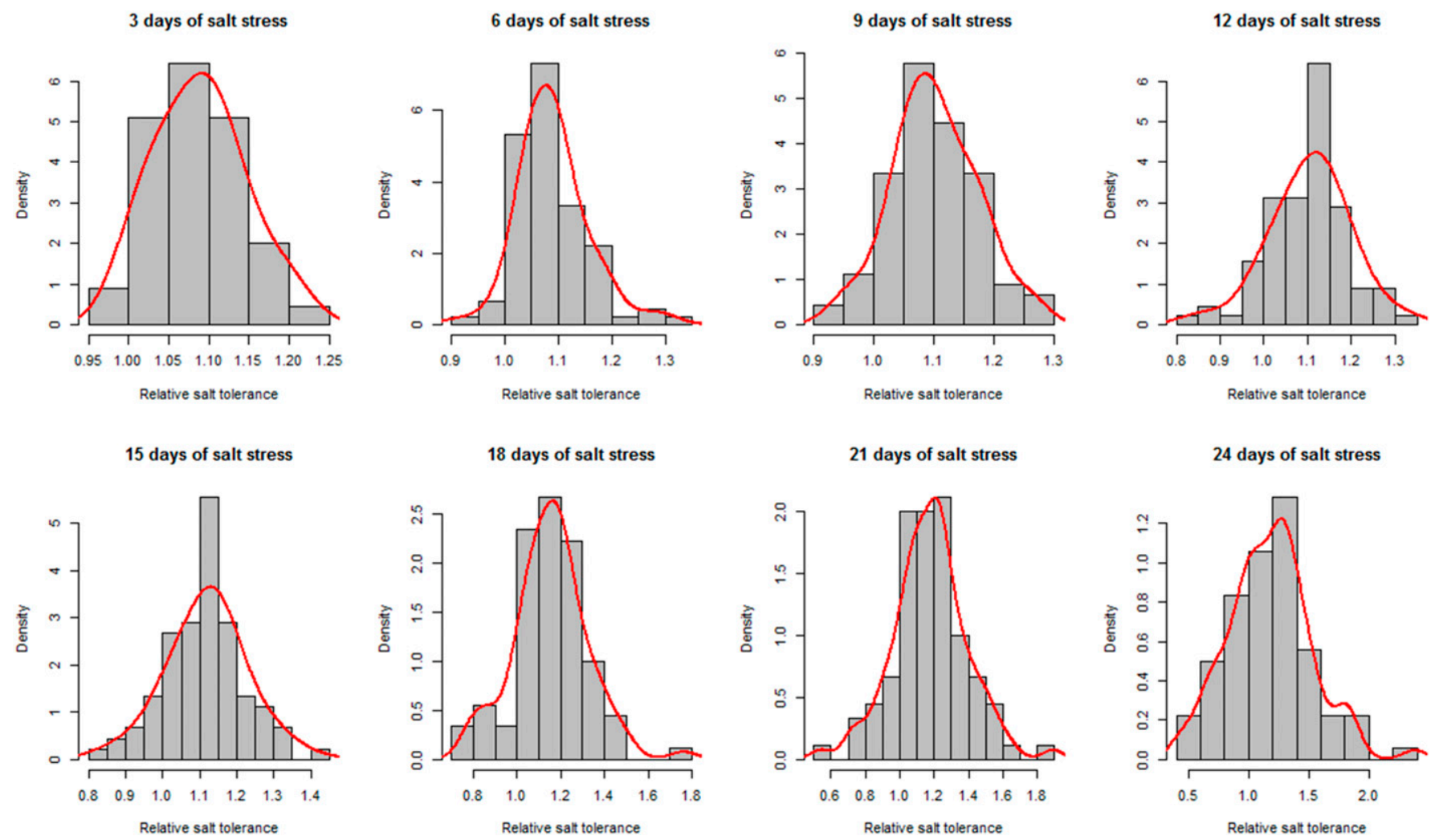

Supplemental Fig. 2. Distributions of relative salt tolerance for chlorophyll content over time. Relative salt tolerance was the ratio between the chlorophyll content under salt stress conditions and without salt stress. 


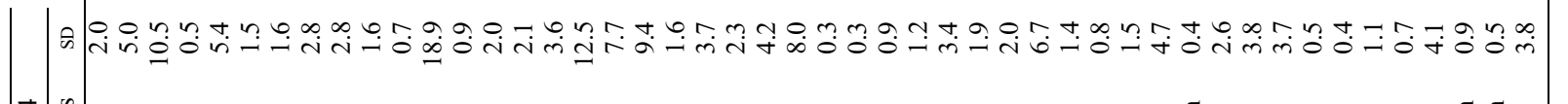

可

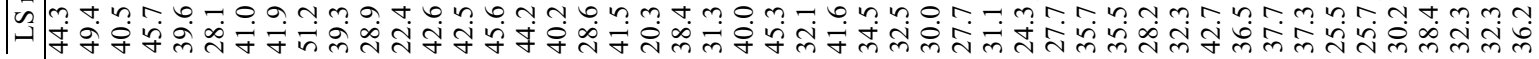
की

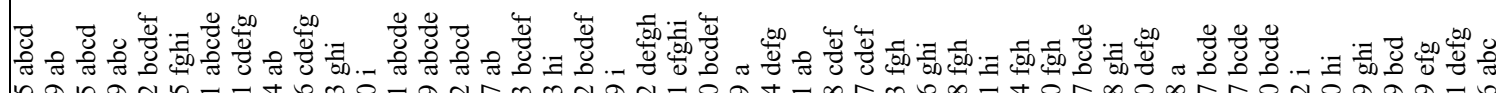

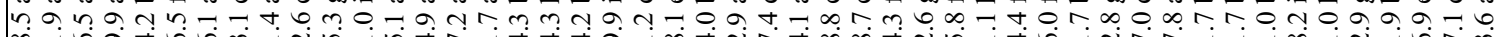

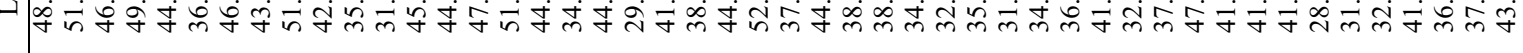
क $\lambda$ i

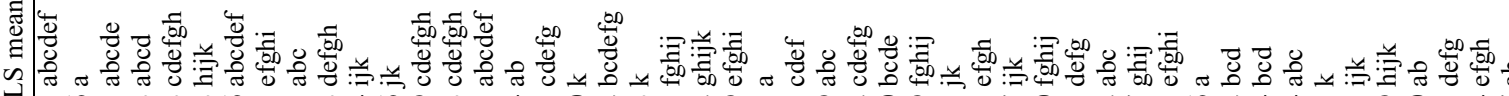

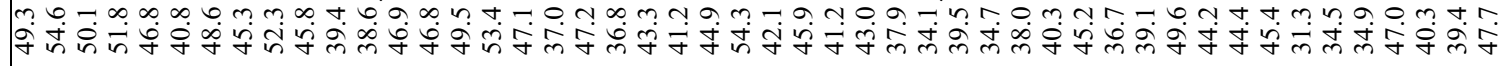
क人

递 尊

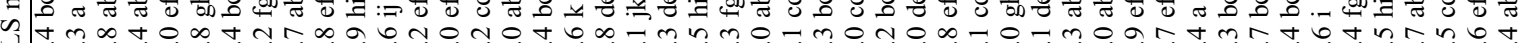

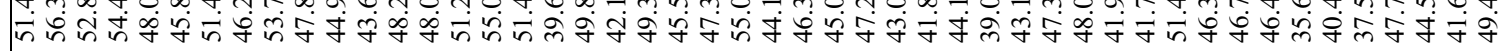
की

馬

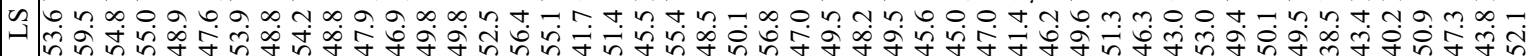

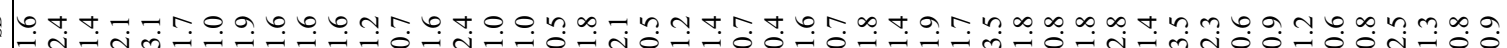

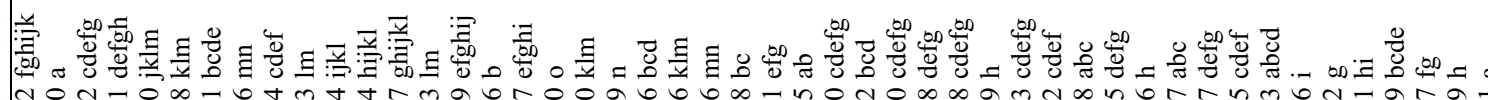

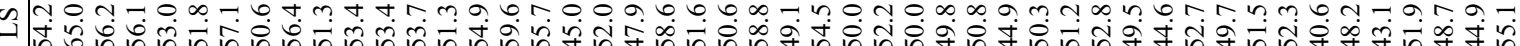

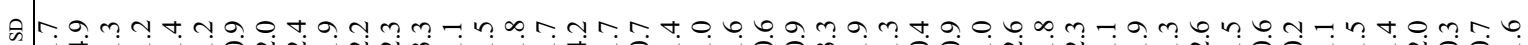

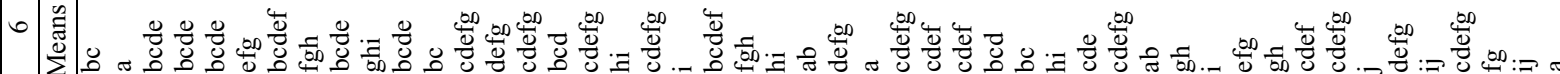

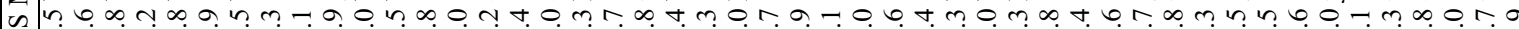

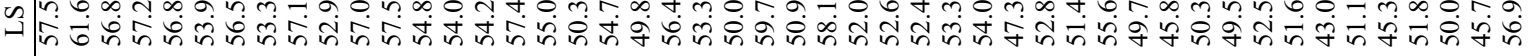
ڤ̆

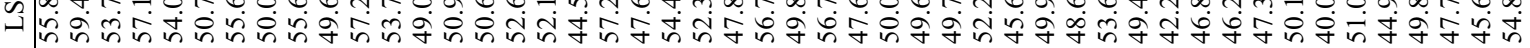

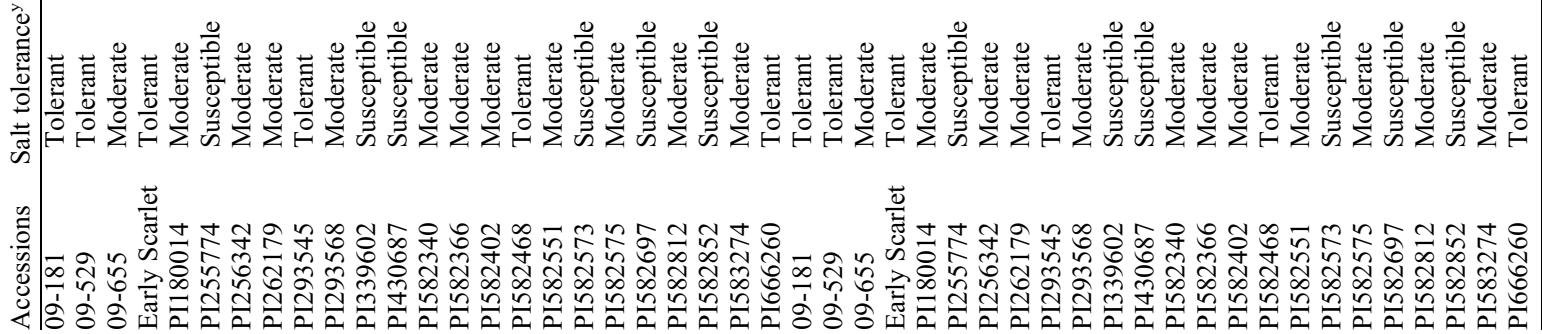




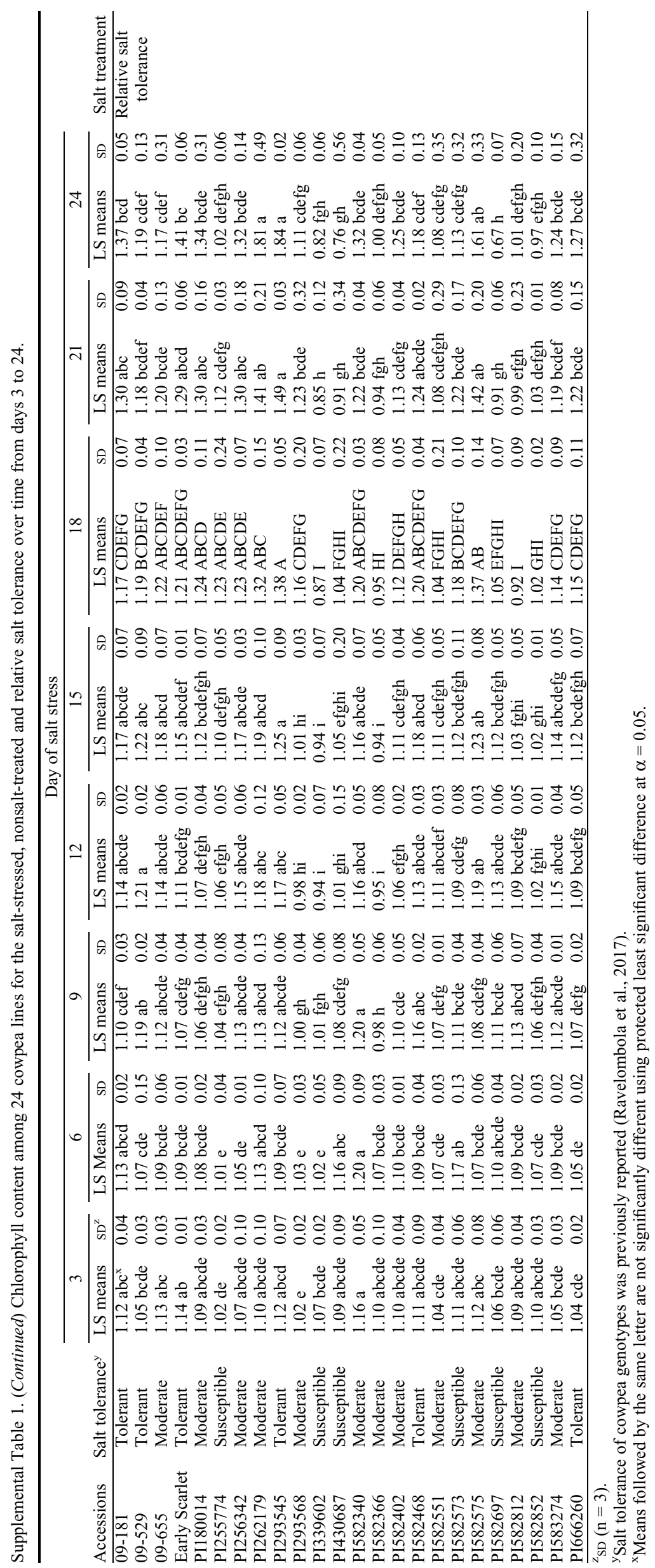


Supplemental Table 2. Chlorophyll (SPAD) content of plants without salt stress and under salt treatment, and relative salt tolerance for chlorophyll content over time.

\begin{tabular}{|c|c|c|c|c|c|c|}
\hline \multirow[b]{2}{*}{ Day of salt stress } & \multicolumn{2}{|c|}{ Chlorophyll of nonsalt-stressed plants } & \multicolumn{2}{|c|}{ Chlorophyll of salt-treated plants } & \multicolumn{2}{|c|}{ Relative salt tolerance $^{z}$} \\
\hline & LS means & SD & LS means & SD & LS means & SD \\
\hline 6 & 51.0 & 3.6 & 55.3 & 2.9 & 1.09 & 0.04 \\
\hline 12 & 47.0 & 3.8 & 51.4 & 4.2 & 1.10 & 0.07 \\
\hline 15 & 44.2 & 3.8 & 49.1 & 4.3 & 1.12 & 0.08 \\
\hline 18 & 40.7 & 4.9 & 46.3 & 5.3 & 1.15 & 0.13 \\
\hline 21 & 37.4 & 4.8 & 43.5 & 6.5 & 1.17 & 0.17 \\
\hline
\end{tabular}

${ }^{\mathrm{z}}$ Relative salt tolerance indicated the ratio between chlorophyll content under salt stress and without salt stress.

Supplemental Table 3. Person's correlation coefficients between the chlorophyll content of salt-stressed plants and chlorophyll content of nonsalt-treated plants, chlorophyll content of plants under salt stress and relative salt tolerance, and chlorophyll content of plants without salt stress and relative salt tolerance over time.

\begin{tabular}{lccc}
\hline Day of salt stress & $\begin{array}{c}\text { Chlorophyll nonstress and } \\
\text { chlorophyll stress }\end{array}$ & $\begin{array}{c}\text { Chlorophyll stress and } \\
\text { relative salt tolerance }\end{array}$ & $\begin{array}{c}\text { Chlorophyll nonstress and } \\
\text { relative salt tolerance }\end{array}$ \\
\hline 3 & 0.75 & 0.26 & -0.44 \\
6 & 0.63 & 0.22 & -0.62 \\
9 & 0.67 & 0.41 & -0.40 \\
12 & 0.55 & 0.46 & -0.48 \\
15 & 0.52 & 0.48 & -0.49 \\
18 & 0.46 & 0.50 & -0.53 \\
21 & 0.43 & 0.67 & -0.37 \\
24 & 0.28 & 0.76 & -0.37 \\
\hline
\end{tabular}

Supplemental Table 4. Shapiro-Wilk test at $\alpha=0.05$ to test for normality of relative salt tolerance.

\begin{tabular}{lcc}
\hline Day of salt stress & Test Statistic $(\mathrm{W})$ & $P$ value $(\operatorname{Pr}<\mathrm{W})$ \\
\hline 3 & 0.97 & 0.061 \\
6 & 0.93 & 0.1769 \\
9 & 0.99 & 0.8151 \\
12 & 0.96 & 0.0661 \\
15 & 0.98 & 0.3158 \\
18 & 0.98 & 0.2108 \\
21 & 0.99 & 0.6974 \\
24 & 0.98 & 0.1779 \\
\hline
\end{tabular}

